\title{
The appropriateness of the macroeconomic imbalance procedure for Central and Eastern European Countries
}

\author{
Geraldine Dany-Knedlik ${ }^{1}$ Martina Kämpfe ${ }^{2}$ (D) Tobias Knedlik $^{2,3}$
}

Published online: 5 February 2020

(c) The Author(s) 2020

\begin{abstract}
The European Commission's Scoreboard of Macroeconomic Imbalances is a rare case of a publicly released early warning system. It was published first time in 2012 by the European Commission as a reaction to public debt crises in Europe. So far, the Macroeconomic Imbalance Procedure takes a one-size-fits-all approach with regard to the identification of thresholds. The experience of Central and Eastern European Countries during the global financial crisis and in the resulting public debt crises has been largely different from that of other European countries. This paper looks at the appropriateness of scoreboard of the Macroeconomic Imbalances Procedure of the European Commission for this group of catching-up countries. It is shown that while some of the indicators of the scoreboard are helpful to predict crises in the region, thresholds are in most cases set too narrow since it largely disregarded the specifics of catching-up economies, in particular higher and more volatile growth rates of various macroeconomic variables.
\end{abstract}

Keywords Macroeconomic Imbalances Procedure (MIP) - Scoreboard · Central and Eastern European Countries (CEEC) · Early warning system · Signals approach · Probit model

Martina Kämpfe

Martina.Kaempfe@iwh-halle.de

Geraldine Dany-Knedlik

gdanyknedlik@diw.de

Tobias Knedlik

Tobias.Knedlik@w.hs-fulda.de

1 Departments of Forecasting and Economic Policy, Macroeconomics, German Institute for Economic Research DIW, Mohrenstraße 58, 10117 Berlin, Germany

2 Department of Macroeconomics, Halle Institute for Economic Research (IWH) - Member of the Leibniz Association, Kleine Maerkerstraße 8, 06108 Halle (Saale), Germany

3 Fulda University of Applied Sciences, Leipziger Str. 123, 36037 Fulda, Germany 


\section{Introduction}

Through the reform process of European institutions in the follow-up to the outbreak of the debt crises in the European Union, the Macroeconomic Imbalance Procedure (MIP) has been enacted as part of the so-called six-pack regulations (European Commission 2011a). Its creation emerged from the fact that macroeconomic imbalances were observed within the Union prior to the crises. The use of an early warning system is an established tool for other international institutions, such as the International Monetary Fund, or national authorities, such as central banks. New features of the scoreboard of the European Commission (EC) compared to other early warning systems include the following: (1) its procedure and results are published; (2) it provides a formal basis for political discussions; and (3) it implies consequences for European Union (EU) member countries that fail to score (Moschella 2014). The political argument behind the MIP is that building up imbalances might not only result in crisis vulnerabilities in single member states, but could also affect other member states negatively, owing to contagion of crises or costly interventions. Consequently, the observation of imbalances results in requests for reform and can, if reform proposals are considered to be inadequate, lead to financial sanctions.

In more detail, EC-Regulation 1176/2011 sets out the principles and rules governing the MIP (European Commission 2011b). It takes a wide approach and leaves room for judgment. It defines four categories of imbalances: "no imbalances", "imbalances", "excessive imbalances", and "excessive imbalances with Excessive Imbalance Procedure (EIP)". The regulation states that the Commission should undertake an "economic reading" of the scoreboard indicators, since underlying economic developments need to be considered. The so-called economic reading is regarded as essential since the nature of the imbalances can vary significantly throughout member states, but it does not clarify the procedure. So far, no fines have been imposed, but several countries have had to endure in-depth reviews and had to subsequently present proposals for economic adjustments to curtail macroeconomic imbalances.

Just as crises resulting from imbalances in member states generate costs for the country of origin as well as the reminder of the EU, costs in the form of reputation losses might also be incurred from being categorised as showing "imbalances". The MIP procedure itself is costly to the taxpayer. Thus, the scoreboard ought to be as precise as possible. It should avoid triggering false alarms, which can result in costly economic adjustment programmes, governmental fines, reputation losses and administrative costs. It should, however, also avoid missing an impending crisis and thus creating costs not only for a single member country but also for the remainder of the Union. To this end, the economic literature suggests a range of different methods for the calibration of early warning systems, especially those that aim to minimize the potential errors of such early warning systems. In this paper, univariate probit estimations are used for the calculation of error-minimizing thresholds and for the assessment of the scoreboard.

In contrast to previous studies, we focus exclusively on Central and Eastern European Countries (CEEC). We believe that the types of crises observed in different 
regions vary in their causes and expressions, as well as in terms of their use of early warning indicators. In particular, we expect that the structural differences of catching-up economies as compared to the rest of the EU become of equal importance for the accuracy of early warning systems. We hypothesise that CEEC show more volatile and higher rates of growth for various macroeconomic variables due to the catching-up process and therefore expect that thresholds set by the EC in the MIP are set too narrow to be optimal thresholds in an early warning system. So far, the MIP takes a one-size-fits-all approach with regard to the identification of thresholds (differentiating between euro and non-euro countries for a few indicators). The aim of this paper is therefore to derive specific optimal thresholds for CEEC.

The paper aims to take stock of the usefulness of the scoreboard by measuring its performance in forecasting crisis and non-crisis periods in CEEC and proposes adjustments of thresholds and indicator selection. Our research question is as follows: Would a specific formulation of thresholds on the scoreboard for CEEC generate better results for the early warning system and therefore fewer costs for member states and the EU? We hypothesize that the construction of specific thresholds of early warning systems for CEEC leads to better forecasting results and therefore to the creation of more appropriate policies.

The paper is structured as follows: in Sect. 2, the methodology employed is described. Section 3 describes the data used. Section 4 presents the results. Concluding remarks are included in Sect. 5.

\section{Methodology}

The method of the EC to derive thresholds, the so-called statistical approach, assumes a certain quantile for the statistical distribution of a variable to be indicative (European Commission 2012a). This, in contrast to the economic literature, is done without defining a dependent variable — no such variable specification has yet been published. Thus, there is no optimization procedure for thresholds with regards to error minimization that could be reproduced in this paper. We rely on the academic literature to derive our optimal thresholds.

The empirical literature on early warning systems uses different approaches that vary with respect to techniques employed. Standard approaches are bivariate logit/probit-models and signals approaches, as presented in Kaminsky and Reinhart (1999). ${ }^{1}$ Logit/probit-models use the bivariate variable crisis/no crisis as the endogenous variable, and estimate the impact of different sets of explanatory variables. ${ }^{2}$ Signals approaches are non-parametric approaches ${ }^{3}$ that examine

\footnotetext{
${ }^{1}$ For a more detailed survey on Early-Warning Systems, see Abiad (2003) and for a test, see Knedlik and Scheufele (2008).

${ }^{2}$ Examples include Berg and Pattillo (1999), Bussière and Fratzscher (2006) and Lo Duca and Peltonen (2013).

${ }^{3}$ These are methods that do not depend on specific assumptions about probability distribution and do not include the fitting of parameters.
} 
the behaviours of potential explanatory variables prior to detected crises and that compare these behaviours with those of non-crises periods. When some variables pass a certain threshold, their changes are used as crisis signals (Brüggemann and Linne 2002; Edison 2003). The disadvantage of the signals approach is its inability to show statistical significance for the derived thresholds. In addition to these two techniques, further concepts outlined in the literature include artificial neural networks, whose advantage is the reflection of complex interaction between the variables (Nag and Mitra 1999; Peltonen 2006; Ristolainen 2018); value-at-risk models (Bléjer and Schumacher 1998); restricted VAR models (Krkoska 2001); Baysian techniques (Christofides et al. 2016); random forests (Alessi and Detken 2018), and Markov-switching approaches, which do not depend on an a priori definition of crises (Abiad 2003; Knedlik and Scheufele 2008).

In this paper, we first employ a signals approach to derive optimal thresholds based on assumed preferences of politicians. Due to various time lags resulting from limited timely data availability levels and politician reaction times, we use a rather long crisis window of 2 years. We drop observations in crisis periods and the 2 years after a crisis due to expected anomalies during these times. We then calculate individual crisis thresholds for each variable that distinguish tranquil periods from crisis periods. The challenge lies in the fact that the threshold must not be too loose (probably not detecting crises) or too tight (probably creating a false alarm). To solve the trade-off between these two forms of error, a utility function for politicians is used as is presented in Alessi and Detken (2011). We assume equal weights on preference to avoid the two types of errors respectively. To derive optimal thresholds, we take a set of economically reasonable thresholds and calculate the losses of these thresholds due to both types of errors. We then use the threshold that minimizes losses in the utility function as the "optimal" threshold. Smaller losses lead to higher utility levels. Thus, the greater the utility level, the better the indicator. The utility value can range from -0.5 to +0.5 . Only indicators with utility values of greater than zero are useful in predicting a crisis. Indicators with non-positive values are left out of further consideration.

Second, we employ univariate-probit pooled-panel models. We are using the fact that the above derived crisis thresholds correspond to a fixed probability of a crisis in a probit model. This allows us to derive confidence bands around the crisis thresholds. In general the probit models take the form of (see, e.g., Wooldridge 2010, chapter 15):

$$
\operatorname{Pr}\left(y_{t}=1 \mid x_{t}\right)=\Phi\left(x_{t}^{\prime} \beta\right) .
$$

We consider $y_{t}$ to be a binary variable that takes the value of zero in tranquil periods and a value of 1 in the 2 years before a crisis as described in Kaminsky et al. (1998). The vector $x_{t}$ consists of just one indicator variable each to derive thresholds. We also include a constant. To calculate the $80 \%$ confidence band we perform a simple bootstrap. In particular, we first calculate the crisis probability of the optimal threshold resulting from the univariate-probit estimation. We call this the optimal crisis probability for now. We then bootstrap the two coefficients of the univariate-probit model from a multivariate normal distribution (100.000 draws) using the estimated 
coefficients and variance-covariance as an approximation of the first and second moments of the distribution. With the bootstrapped coefficients, we are able to calculate the distribution of optimal thresholds that correspond to the optimal crisis probability. We report the 10th and 90th percentile of the distribution of optimal thresholds to indicate the $80 \%$ lower and upper confidence bands.

In a third step, we include all indicators of significance into a multivariate-probit pooled-panel model to test for the overall explanatory power of the early warning system.

\section{Data}

The first step in constructing an early warning system is defining crisis periods. In regard to, the MIP scoreboard, it is not clearly defined which types of crises are meant to be signalled. It can, however, be assumed that politicians were aware of the types of crises that the European Union was facing at the time of the scoreboard's introduction. The crises emerged from macroeconomic imbalances, which in some cases led to financial crises and in other cases resulted in public-debt crises. Since the initial scoreboard design was established, the Commission has undertaken several adjustments of indicators as well as data revisions and threshold updates (in 2012, 2013 and 2015), but not in the direction which this paper suggests, namely the consideration of the specificities of CEEC.

A public-debt crisis can be understood as a state in which governments fail to or have difficulty in repaying their debts. One obvious empirical definition of publicdebt crisis might therefore be a government default. This definition might be too narrow, if one considers that a default might just have been avoided as a result of assistance from European or international institutions, or even other governments. Thus, a second possibility to define a crisis empirically might be to refer to situations when International Monetary Fund or the European Union programmes have been provided to a country in crisis. This approach is, however, also not without its problems. First, these programmes usually only start after a crisis has happened. Thus, the dating of the crisis might be too late. Second, the crisis might be stopped by measures other than programmes of international institutions. For example, the Central Bank could announce that it will do whatever it takes to avoid defaults. In this case, the crisis might be overcome without any programme in place. Therefore, in this paper, other types of definition are used.

Countries typically default on their debts when refinancing becomes too expensive due to increased risk premiums on government bonds or loans. A high spread of government-bond yields can be interpreted as a serious doubt in a government's capacity to service its debt in the future. As the reference in spreads, we use the average of the yields of AAA-rated countries of the European Monetary Union (EMU). Thus, the spread between government bond yields and a riskless reference rate is used as the first definition of debt crises in this paper, as described in Knedlik and von Schweinitz (2012). As high government-bond spreads do not necessarily lead to default, we refer to these events as times of 'fiscal stress' or 'crisis'. Data on 10-year government-bond yields are taken from Eurostat and IMF International 
Table 1 Crisis dates. Sources: Nominal and real spreads: own calculations based on Eurostat, IMF International Financial Statistics and Thomson Reuters; Systemic financial crises: Lo Duca et al. (2017)

\begin{tabular}{llll}
\hline & Nominal spreads & Real spreads & $\begin{array}{c}\text { Systemic } \\
\text { financial } \\
\text { crises }\end{array}$ \\
\hline $\begin{array}{l}\text { Bulgaria } \\
\text { Czech Republic }\end{array}$ & 2009 & 2014,2016 & $2007-2011$ \\
Estonia & $1999-2002,2008-2009$ & $1999-2000,2009$ & $2007-2010$ \\
Croatia & $2009,2011-2012,2016$ & $2010-2012,2015-2016$ & $2009-2010$ \\
Lithuania & $2009-2010$ & $2009-2010$ & 1999 \\
Latvia & 2009 & $2001-2003,2009$ & 1999 \\
Hungary & $2004-2006,2008-2014$ & $2011,2013-2014$ & $2007-2009$ \\
Poland & 2001 & 2016 & \\
Romania & $2005-2006,2008-2012$ & & $2009-2010$ \\
Slovenia & $2002,2012-2013$ & $2012-2013$ & \\
Slovakia & & & \\
\hline
\end{tabular}

Financial Statistics and AAA-rated government-bond yields are taken from Thomson Reuters. Fiscal stress is present when the spread exceeds the mean of all spreads by more than one standard deviation.

However, since CEEC have, in part, their own domestic currencies in place and show heterogeneous inflation developments, nominal spreads of interest rates might simply reflect inflation differentials that could mask real spreads and therefore fiscal stress. Thus, we apply, as a second crisis definition real interest rate differentials by employing Eurostat data on consumer price inflation. Again, fiscal stress is indicated when the real spread exceeds the mean of all real spreads by more than one standard deviation.

For a third crisis definition, we broaden the scope beyond fiscal stress and assume that the scoreboard could also be meant to signal a financial crisis in the banking sector. We refer to Lo Duca et al. (2017) and use their systemic financial crises identification. An overview over all crisis periods is presented in Table 1. Since the sample of Lo Duca et al. (2017) ends in 2016 and interest rate spreads are not available before 1999 for most countries under observation, we limit our sample to the years 1999-2016.

As explanatory variables, which are meant to indicate upcoming crises, we exclusively use the indicators of the MIP scoreboard. The use of official Eurostat data also defines the data frequency (annually).

The scoreboard consists of 14 indicators denoting the presence of macroeconomic imbalances (see European Commission 2012a, b). Scoreboard indicators include: the current account balance relative to GDP, the net international investment position to GDP, the export market share, nominal unit labour costs, the real effective exchange rate, private sector debt relative to GDP, the flow of credit to the private sector, house prices, general government-sector debt relative to GDP, the unemployment rate, the total financial sector liabilities, the activity rate, the long-term 
unemployment rate, and the youth unemployment rate. Official thresholds for these indicators are shown in Table 3. The selection of the indicator variables emerged from political as well as academic debates. What is more, this selection has sometimes been driven by opposing aims. One example is that for reasons of transparency, the scoreboard was aimed at including as few indicators as possible. However, for better results, the early warning systems should include as many good indicators as are available. This is particularly important because the characteristics of newly emerging crises might be different from those of past crises. In the present analysis, we use the original annual scoreboard data provided by the EC. This also implies that data is not always available for all years in all countries under consideration.

The first indicator is the current account balance. It is expressed as the 3-year backward-looking moving average of the ratio of the current account balance to GDP. The threshold defined by the EC is two-sided. Thus, signals are sent if the realization of the current-account-balance-to-GDP ratio is below $-4 \%$ or above $+6 \%$ for all countries. The current account balance is probably the most obvious indicator for international macroeconomic imbalances. Continued deficits might indicate a loss of international competitiveness and therefore a risk of crises. Longer lasting surpluses do not constitute risks for the surplus country, but rather for all other countries.

The second indicator is the net international investment position, which accumulates current account balances over time. It indicates whether the short-term currentaccount imbalances are levelled over time or accumulate to larger foreign indebtedness. Also, this indicator is expressed as a ratio to GDP. The threshold is set at $-35 \%$ for all countries. Thus, if the net international investment position is less than $-35 \%$ of GDP, the indicator is sending a signal.

The third variable is the change in the export market share over 5 years. If a country loses more than $6 \%$ of its share in export markets, a signal is sent. That threshold is given by the EC for all countries. In addition, this variable addresses issues of competitiveness. It only takes the export side of the current account and compares it to international competitors. Thus, it is focused on the balance sheet total instead of its balance.

The fourth indicator is nominal unit labour costs. The EC uses the percentage change of nominal unit labour costs over 3 years. While the above-described indicators can be interpreted as results of losing or gaining competitiveness, the unit labour costs can be seen as one cause of the changing competitiveness of economies. Unit labour costs not only measure changes in wages but rather combine changes in wages with changes in productivity. If wages increase faster than productivity, unit labour costs increase. If wage increases are less than productivity increases, unit labour costs decline. Thus, with this indicator, the threshold depends on belonging to the Eurozone. For euro countries, the threshold is $9 \%$, for non-euro countries a signal is sent if the unit labour costs increase by more than $12 \%$ over that period of time.

The fifth indicator is the real effective exchange rate. The Commission uses the percentage change of the real effective exchange rate, based on consumer prices over 3 years and a basket of 42 trading partners. A change in the real effective exchange rate therefore indicates a change in relative consumer prices. It is, just as with unit 
labour costs, an indicator of a potential cause of changes in competitiveness. If domestic prices increase relative to foreign prices by more than what a change in the nominal exchange rate compensates for, a country faces a real currency appreciation. This means that it might face difficulties in selling domestic goods on international markets. Also with this indicator, the EC differentiates between euro countries and non-euro countries, and the threshold is two-sided; the threshold for Eurozone countries is $\mp 5 \%$, and for non-euro countries $\mp 11 \%$.

The sixth indicator is private sector debt, which is expressed as a ratio to GDP. The official threshold for all countries is $133 \%$. If the level of private debt exceeds this threshold, a signal is sent. With this sixth indicator, the scoreboard turns towards domestic imbalances in the European economies. Private sector debt here means the debt of the private sector excluding banks. The time before the crisis reveals a large increase in private debt, which indicates increased vulnerability to banking crises and might signal the potential for fuelling asset-price bubbles.

The seventh indicator is the flow of credit to the private sector. Thus, it is the flow component to the stock of private-sector debt. This might indicate credit-fuelled asset price bubbles or vulnerabilities and is expressed as a ratio to GDP. If credit to the private sector exceeds $14 \%$ of GDP the indicator sends a signal. The threshold is applicable to all countries.

The eighth indicator is the house-price index and measures the percentage change of deflated house prices over the previous year relative to the consumption deflator. The threshold is the same for all countries. If the relative increase in house prices exceeds $6 \%$, the indicator sends a signal. The house-price indicator is included in the scoreboard because house prices have been observed to increase in some countries, namely Spain and Ireland or Latvia before the crisis. The reversal of asset-price bubbles in the property sector leads to the credit defaults that contributed to the banking crises.

The ninth indicator is general government-sector debt. It is defined by the Maastricht criterion and is expressed in relation to GDP. If public debt is greater than $60 \%$ of GDP, a signal is sent. Again, this threshold is used for all countries. The publicdebt indicator is the only one that was also used before the debt crises in Europe, but with limited success.

The tenth indicator is the unemployment rate. The EC calculates a 3-year, backward-looking moving average. The universal threshold for all countries is $10 \%$. The unemployment rate is meant to reflect the efficiency and flexibility of economies to use their scarce resources in the production process. Thus, persistently high levels of unemployment might indicate a limited ability to adjust to economic developments.

The eleventh indicator, introduced after the first application of the scoreboard in the MIP, is that of total financial-sector liabilities. ${ }^{4}$ The financial sector was ignored in the initial scoreboard, although the recent crises arose from this sector in many European countries. If the financial sector expands very quickly, it might indicate that the banking sector is taking excessive risks, which can consequently enhance

\footnotetext{
${ }^{4}$ For the addition of a financial sector indicator, see European Commission (2012c).
} 
the vulnerability of that sector to economic shock. The scoreboard's threshold for the annual change in the liabilities of the financial sector-the same for all countries of the European Union-lies at $16.5 \%$.

In the fifth annual round of the MIP in 2015, three employment indicators were added to the main scoreboard. ${ }^{5}$ The inclusion of new employment variables should strengthen the analysis of macroeconomic imbalances by the EC. Thus, the twelfth indicator is the activity rate, defined as the number of active population (employed and unemployed) aged 15-64 over total population of the same age range, expressed in 3-year change. The scoreboard's threshold for all European countries is $-0.2 \%$. Between 2013 and 2014, an increase of between 0.2 and $0.3 \%$ was recorded in almost all countries in the EU, which can largely be attributed to the structural increase in the number of women and older workers participating in the labour market.

The thirteenth indicator is the long-term-unemployment rate of the active population aged 15-74, as percentage change over the last 3 years. The threshold lies at $0.5 \%$. The persistence of long-term unemployment has implications for the efficiency of labour-market matching and the risk that unemployment becomes entrenched.

The fourteenth indicator is the youth unemployment rate of the active population aged 15-24, as a percentage point change over the last 3 years. The threshold lies at $2 \%$. The youth unemployment rate is an early indicator of worsening labour market conditions. It also signals lowered potential output (via a loss of skills formation, scarring effects, and foregone earnings in the future) and is associated with a higher level of social exclusion.

Some summary statistics of the indicators is depicted in Table 2.

The observation of various indicators supports our hypothesis. For the current account indicator, the MIP threshold of $-4 \%$ is already crossed on average, while pre-crisis values range between -6.3 and $-8.0 \%$, depending on the type of crisis. Fluctuation of the real effective exchange rate are, for some types of crises even lower in pre-crisis periods as compared to tranquil periods. The export market share does not drop on average in pre-crisis periods. Unit labour costs increase on average by $27 \%$ in CEEC, quite significantly above the MIP threshold of $12 \%$ for noneuro countries. In addition, the unemployment rate is on average already above the MIP threshold. Changes in the activity rate are on average positive in pre-crisis periods, contrary to the $-0.2 \%$ threshold of the MIP and long-term unemployment as well as youth unemployment which seems to decrease on average before crises and not to increase as the MIP threshold suggests. As it would be assumed for catching up economies, levels of the international investment position are largely negative, with $-55 \%$ on average below the MIP's threshold of $-35 \%$ and private debt levels of $133 \%$ (the MIP threshold) can only be found in five out of 196 observations. Similarly, public debt levels of about $60 \%$ are only found in three countries and not always in the periods preceding crises.

\footnotetext{
${ }_{5}^{5}$ For the addition of employment indicators, see European Commission (2015a, b).
} 


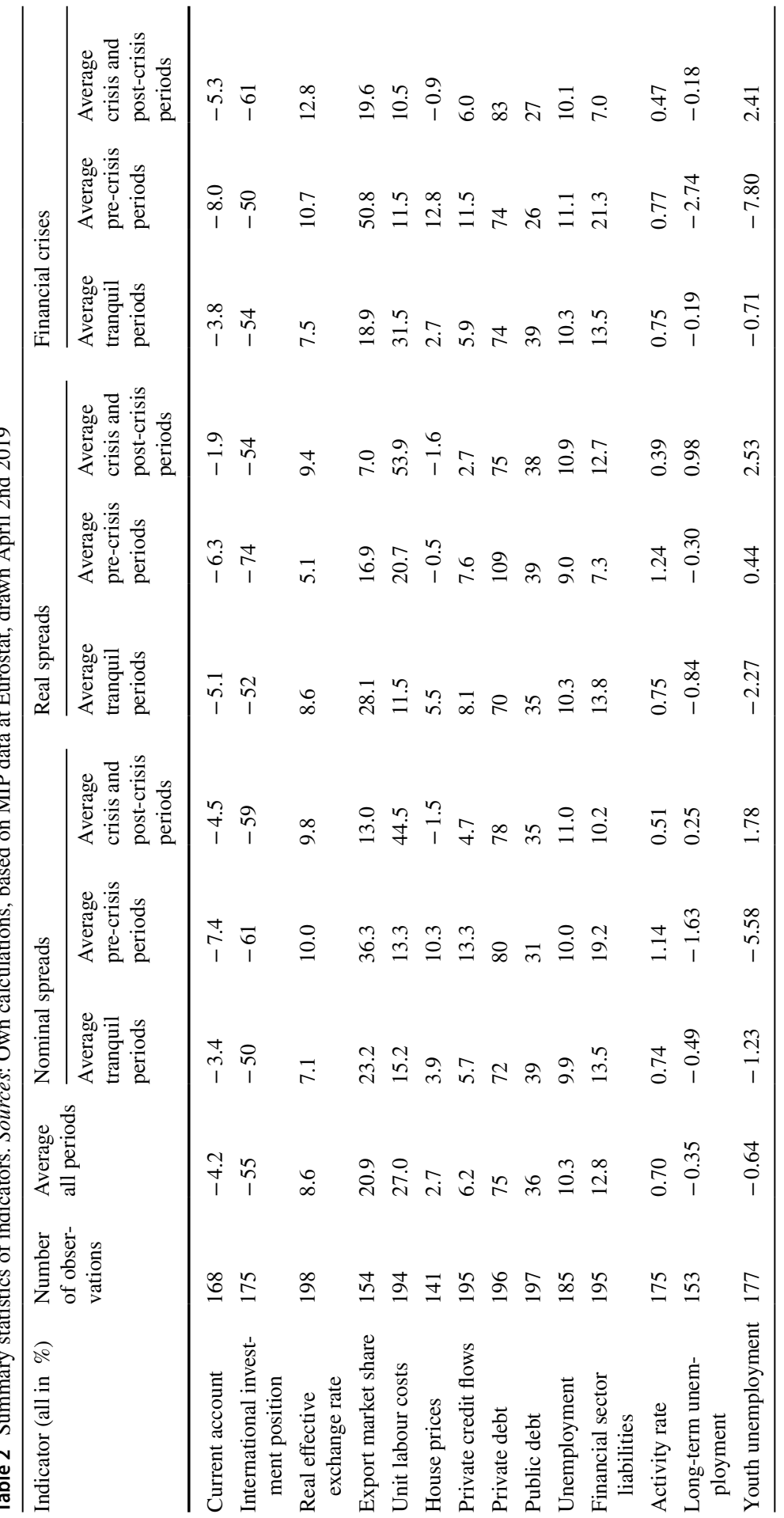




\section{Results}

Table 3 presents the results of calculating optimal thresholds using the signals approach. Out of the 32 optimal thresholds that yield positive utility, we have found 19 optimal thresholds to be wider as compared to the MIP's thresholds and ten optimal thresholds to be narrower. In just three cases, we have found the optimal thresholds to be in line with the thresholds employed in the MIP.

In more detail, we have found for the current account, the optimal threshold between -6 and $-11 \%$ to be wider when compared to the official threshold of $-4 \%$ for all types of crises. We do not consider the upper threshold of $+6 \%$ of the MIP, since it yields negative utility for all types of crises. Similar the optimal thresholds for the international investment position with between -41 and $-70 \%$ are wider as the MIP's threshold of $-35 \%$. Regarding the real effective exchange rate, we have found negative utility for real spreads (and exclude that threshold from further analysis). For nominal spreads the optimal threshold is wider as the proposed threshold of the MIP, while for financial crises the optimal threshold (₹6\%) would be more narrow. The export market share-threshold is producing non-positive utility for nominal spreads as well as for financial crises. For real spreads, the optimal threshold $(-5 \%)$ is near the MIP's threshold of $-6 \%$. For unit labour costs we find a more narrow optimal threshold for the case of nominal spreads, an optimal threshold of $12 \%$ in line with the MIP's threshold for real spreads and a wider optimal threshold for financial crises. For house prices, we have found no positive utility for the case of real spreads while for the two other types of crises a wider, $11 \%$ threshold would be optimal. For private credit flows, the optimal thresholds would be narrower with regard to nominal spreads (5\%) and financial crises (8\%) and wider for real spreads (24\%) when compared to the MIP's threshold of 14\%. With a range of between 100 and $120 \%$ the optimal threshold would again be narrower when compared to the MIP's threshold of $133 \%$ for private debt. The optimal threshold for the public debt indicator yields no positive utility for the case of financial crises, while the optimal threshold for real spreads (45\%) would be narrower and for nominal spreads (80\%) wider than the MIP's threshold of $60 \%$. Besides the non-positive utility for the case of real spreads, we have found the optimal thresholds of the unemployment at $11 \%$ for nominal spreads and $10 \%$ for financial crises to be close to the MIP's threshold of 10\%. The optimal thresholds for the financial sector liabilities are between 23 and $27 \%$ wider for all types of crises when compared to the MIP's threshold of $16.5 \%$. The MIP's threshold for the activity rate of $-0.2 \%$ has been found to be too narrow for the cases of nominal and real spreads and too wide for financial crises. The longterm employment and youth unemployment indicators yield no positive utility for nominal spread crises and financial crises but positive utility for real spread crises where for both indicators the MIP's threshold is set too narrow.

While the results tend to support our hypothesis, the non-parametric signals approach does not allow for conclusions regarding the statistical significance of the findings. In particular, we cannot be sure (1) whether the optimal thresholds are significantly different from zero and (2) whether the optimal thresholds are significantly different from the thresholds proposed by the MIP. To this end, the results of the 


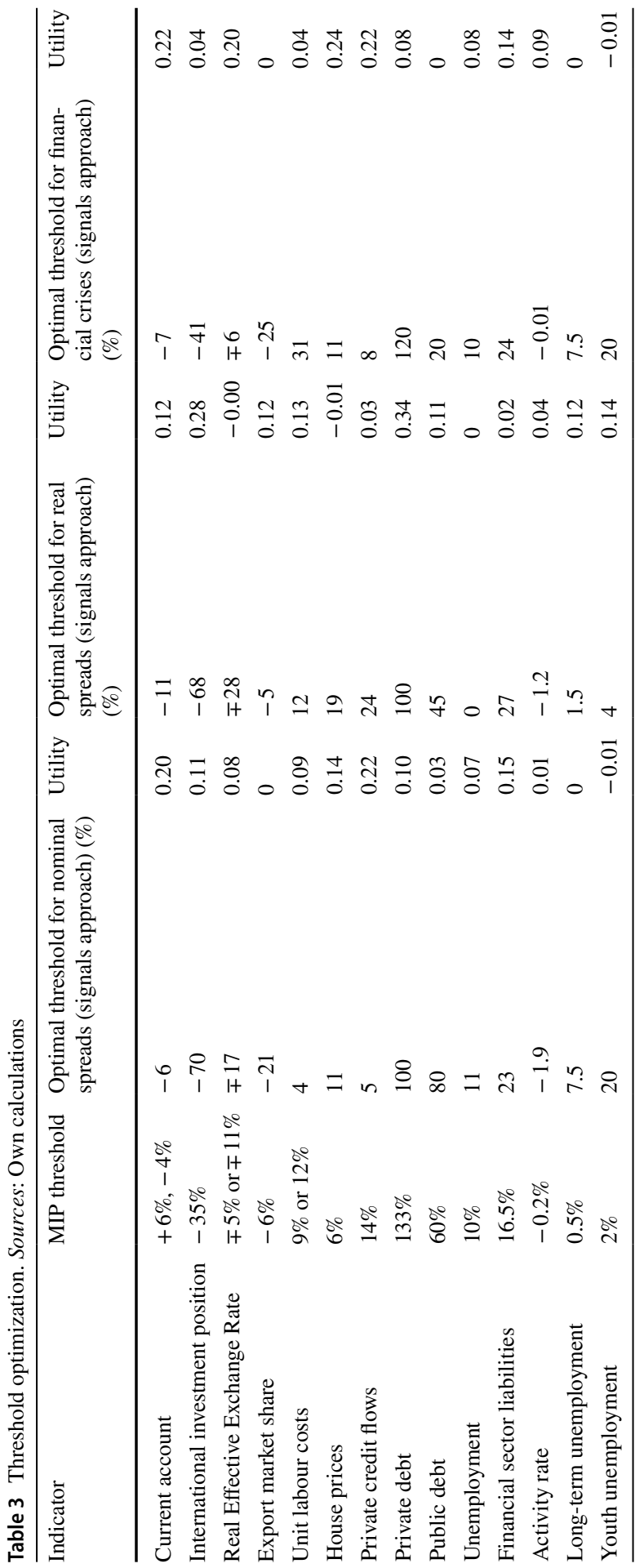


univariate panel estimations and the calculated thresholds are presented in Table 4. It shows that out of the 32 thresholds with positive utility, we have found just 14 thresholds to be significantly different from zero. Out of the 14 significant thresholds, six are significantly different from the MIP's threshold using a $80 \%$ confidence band. In four of the later cases (the current account, financial sector liabilities and the international investment position for two types of crises), we find the official threshold being too narrow, not taking the dynamics of emerging market economies into account. In two of the cases (private credit flows and private debt), the official thresholds are too wide, neglecting the specifics of CEEC, e.g. that debt levels of other EMU countries are not (yet) been reached.

Results for multivariate estimations are presented in Table 5.

For all three models, we have found satisfying coefficients of determination, indicating that the models have explanatory power. Looking at the signs and significance of individual coefficients shows that taking cross-dependencies and potential collinearity of variables into account leads to insignificance of the contributions of some of the variables. However, all variables with significant coefficients show the same signs as in the univariate models, thus confirming the appropriateness of the calculated optimal thresholds.

\section{Conclusions}

For the three types of crises considered in this paper, we were able to derive 14 optimal thresholds that are useful and are statistically significant in the univariate models. Out of the 14 significant thresholds, six have been found for the case of nominal spreads as crisis variable, while for the cases of real spreads and financial crises only four significant indicators have been found.

For nominal spread crises, the current account, the international investment position, house prices, private credit flows, public debt and financial sector liabilities have been found to be significant and useful. For real spread crises, the international investment position, unit labour costs, private debt, and financial sector liabilities have been found to be significant and useful. For financial crises, the current account, house prices, private credit flows, and financial sector liabilities turn out to be significant and useful. Thus, among the indicators there are five indicators with significant and useful thresholds for at least two of the three types of crises. These are the current account, the international investment position, house prices, private credit flows and financial sector liability.

For four of these indicators (current account, international investment position, house prices, and financial sector liabilities) the thresholds set by the MIP are set too narrow when compared to the optimal threshold. For the private credit flow indicator the MIP's threshold is too wide when compared to the optimal threshold.

In six of the 14 cases of significant thresholds, the thresholds are also significantly different from the official thresholds. In those cases, the thresholds should be adjusted accordingly. However, in eight of the 14 cases of significant thresholds the calculated optimal thresholds are not significantly different from the MIP's thresholds. The use of these indicators in the MIP is appropriate. The economic reading 


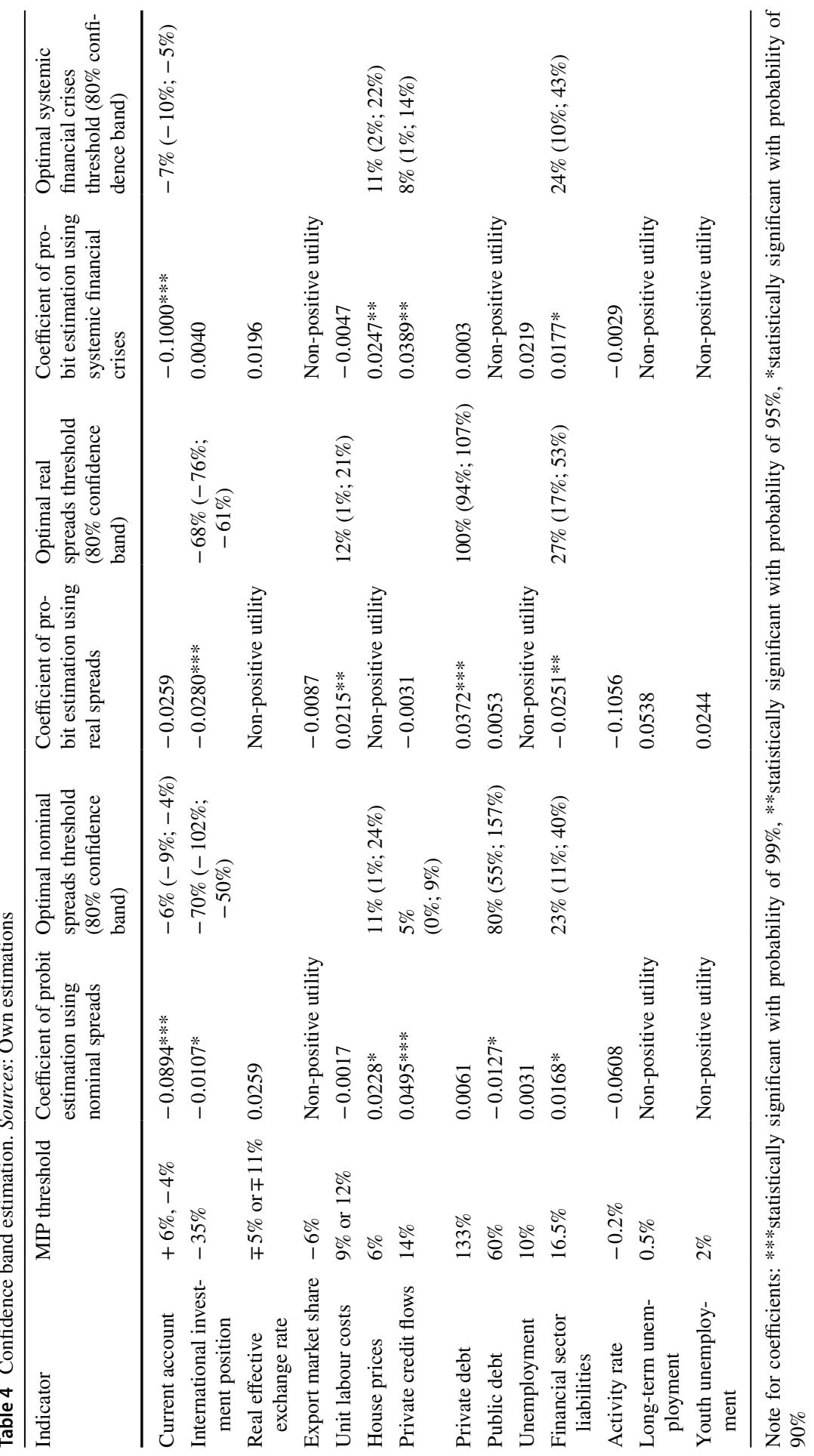




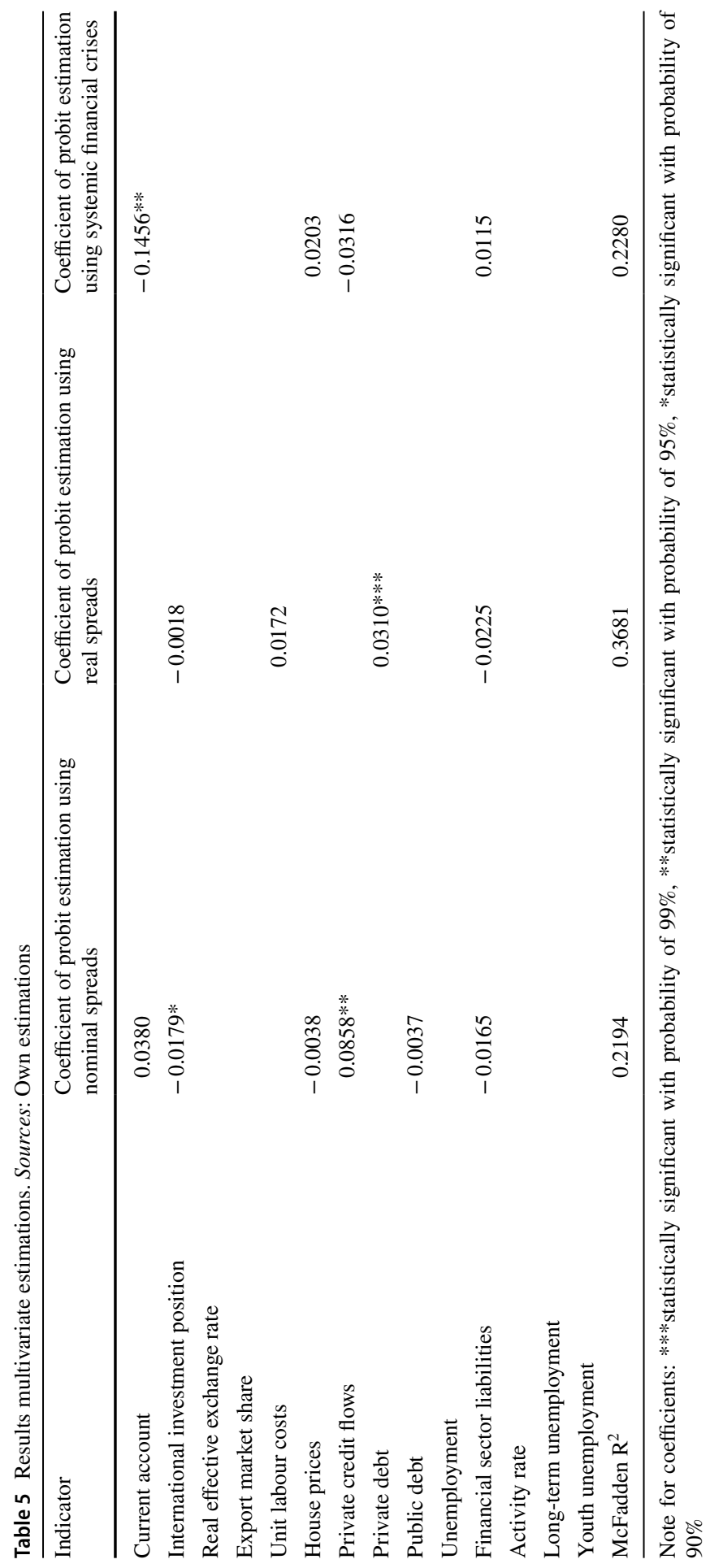


should be focused on the 14 significant indicators. Since the thresholds are set too narrow in many cases, the issuing of alarms or the calling of imbalances should be done with caution.

For six indicators, namely the real effective exchange rate, the export market share and four labour market indicators (unemployment, activity rate, long-term unemployment, youth unemployment) no significant and meaningful thresholds could be found. These indicators are recommended to be dropped from the scoreboard for CEEC.

Today, the EC follows a one-size-fits-all approach with the exception of differentiating between euro and non-euro countries on two indicators. More important than nominating a currency would be to differentiate between member countries based on historical levels of indicator variables and their differing dynamics. Based on our analysis, we recommend dropping of indicators with no use in predicting any type of crises and the adjustment of threshold values. In particular, we recommend adjusting specific threshold values for central and eastern European economies. Furthermore, as the pattern of economic development in all member countries might change over time, we would recommend deeper research into the longer economic dynamics and potentially necessary adjustments of indicative thresholds for all countries. Until this is implemented, we recommend treating the signals of the MIP scoreboard with caution, in particular for CEEC.

Acknowledgements Open Access funding provided by Projekt DEAL.

Open Access This article is licensed under a Creative Commons Attribution 4.0 International License, which permits use, sharing, adaptation, distribution and reproduction in any medium or format, as long as you give appropriate credit to the original author(s) and the source, provide a link to the Creative Commons licence, and indicate if changes were made. The images or other third party material in this article are included in the article's Creative Commons licence, unless indicated otherwise in a credit line to the material. If material is not included in the article's Creative Commons licence and your intended use is not permitted by statutory regulation or exceeds the permitted use, you will need to obtain permission directly from the copyright holder. To view a copy of this licence, visit http://creativecommons.org/licen ses/by/4.0/.

\section{References}

Abiad AG (2003) Early warning systems: a survey and a regime-switching approach. IMF working paper $2003 / 32$

Alessi L, Detken C (2011) Quasi real time early warning indicators for costly asset price boom/bust cycles: a role for global liquidity. Eur J Polit Econ 27(3):520-533

Alessi L, Detken C (2018) Identifying excessive credit growth and leverage. J Financ Stab 35:215-225

Berg A, Pattillo C (1999) Predicting currency crises: the indicators approach and an alternative. J Int Money Financ 18(4):561-586

Bléjer MI, Schumacher L (1998) Central Bank vulnerability and the credibility of commitments: a valueat-risk approach to currency crises. IMF working paper 1998/65

Brüggemann A, Linne T (2002) Are the central and eastern european transition countries still vulnerable to a financial crisis? Results from the Signals Approach. Halle Institute of Economic Research (IWH) discussion paper no 157

Bussière M, Fratzscher M (2006) Towards a new early warning system of financial crises. J Int Money Finance 25(6):953-973 
Christofides C, Eicher TS, Papageorgiou C (2016) Did established early warning signals predict the 2008 crises? Eur Econ Rev 81:103-114

Edison HJ (2003) Do indicators of financial crises work? An evaluation of an early warning system. Int J Financ Econ 8(1):11-53

European Commission (2011a) EU Economic governance "Six-Pack" enters into force, at: http://europ a.eu/rapid/press-release_MEMO-11-898_en.htm. Accessed 17 Mar 2017

European Commission (2011b) Regulation (EU) No 1176/2011 of the European Parliament and of the Council of 16 November 2011 on the prevention and correction of macroeconomic imbalances, at: http://eur-lex.europa.eu/LexUriServ/LexUriServ.do?uri=OJ:L:2011:306:0025:0032:EN:PDF

European Commission (2012a) Scoreboard for the surveillance of macroeconomic imbalances: envisaged initial design. European Economy. Occasional papers 92, at: http://ec.europa.eu/economy_finance/ publications/occasional_paper/2012/pdf/ocp92_en.pdf

European Commission (2012b) Alert Mechanism Report 2012, COM 068 final, at: http://eur-lex.europ a.eu/legal-content/EN/TXT/PDF/?uri=CELEX:52012DC0068\&from=EN

European Commission (2012c) Completing the Scoreboard for the MIP: Financial Sector Indicator SWD 389, at: http://ec.europa.eu/eurostat/documents/16624/6180184/Completing+the+Scoreboard +for+the+MIP_Financial+Indicator_SWD\%282012\%29389+final.pdf/5ca18df9-ed04-436d-a85bb2a2953d46a5

European Commission (2015a) Alert Mechanism Report 2016, COM 691 final, at: http://eur-lex.europ a.eu/legal-content/EN/TXT/PDF/?uri=CELEX:52015DC0691\&from=EN

European Commission (2015b) Adding employment indicators to the scoreboard of the Macroeconomic Imbalance Procedure to better capture employment and social developments. Ref. Ares(2015)5426195, at: https://ec.europa.eu/info/sites/info/files/employment_indicators _mip_en.pdf

Kaminsky G, Reinhart CM (1999) The twin crises: the causes of banking and balance-of-payments problems. Am Econ Rev 89(3):473-500

Kaminsky G, Lizondo S, Reinhart CM (1998) Leading indicators of currency crises. IMF Staff Pap 45(1): $1-48$

Knedlik T, Scheufele R (2008) Forecasting currency crises: which methods signalled the South African currency crisis of June 2006? S Afr J Econ 76(3):367-383

Knedlik T, von Schweinitz G (2012) Macro-economic imbalances as indicators for Debt Crises in Europe. J Common Mark Stud 50(5):726-745

Krkoska L (2001) Assessing macroeconomic vulnerability in Central Europe. Post-Communist Econ 13(1):41-55

Lo Duca M, Peltonen TA (2013) Assessing systemic risks and predicting systemic events. J Bank Finance 37(7):2183-2195

Lo Duca M, Koban A, Basten M, Bengtsson E, Klaus B, Kusmierczyk P, Lang JH, Detken C, Peltonen T (2017) A new database for financial crises in European Countries-ECB/ESRB EU crises database. ECB occasional paper no 194

Moschella M (2014) Monitoring Macroeconomic Imbalances: is EU surveillance more effective than IMF surveillance? J Common Mark Stud 52(6):1273-1289

Nag AK, Mitra A (1999) Neural networks and early warning indicators of currency crisis. Reserve Bank India Occas Pap 20(2):183-222

Peltonen TA (2006) Are emerging market currency crises predictable? A test. ECB working paper no 571

Ristolainen K (2018) Predicting banking crises with artificial neural networks: the role of nonlinearity and heterogeneity. Scand J Econ 120(1):31-62

Wooldridge JM (2010) Econometric analysis of cross section and panel data, 2nd edn. MIT Press, Cambridge

Publisher's Note Springer Nature remains neutral with regard to jurisdictional claims in published maps and institutional affiliations. 